Article

\title{
Effect of Ultrafiltration of Pitaya Extract (Stenocereus thurberi) on Its Phytochemical Content, Antioxidant Capacity, and UPLC-DAD-MS Profile
}

\author{
Daniela D. Castro-Enríquez ${ }^{1}{ }^{\circledR}$, Beatriz Montaño-Leyva ${ }^{1}$, Carmen L. Del Toro-Sánchez ${ }^{1}$, \\ Josué E. Juárez-Onofre ${ }^{2} \mathbb{D}$, Elizabeth Carvajal-Millán ${ }^{3}\left(\mathbb{D}\right.$, Guadalupe A. López-Ahumada ${ }^{1}$, \\ Carlos G. Barreras-Urbina ${ }^{1}\left(\mathbb{D}\right.$, José A. Tapia-Hernández ${ }^{1} \mathbb{D}$ and Francisco Rodríguez-Félix ${ }^{1, *}$ \\ 1 Department of Food Research and Graduate Program, University of Sonora, Hermosillo 83000, Sonora C.P., \\ Mexico; daniela.castro.e@hotmail.com (D.D.C.-E.); beatriz.montano@unison.mx (B.M.-L.); \\ carmen.deltoro@unisonmx.onmicrosoft.com (C.L.D.T.-S.); amanda.lopez@unison.mx (G.A.L.-A.); \\ carlosgbarrerasu@gmail.com (C.G.B.-U.); tapia_hernandez_agustin@hotmail.com (J.A.T.-H.) \\ 2 Department of Physical, University of Sonora, Hermosillo 83000, Sonora C.P., Mexico; \\ josue.juarez@unison.mx \\ 3 Research Center for Food and Development, A.C. Biopolymers-CTAOA, Hermosillo 83304, Sonora C.P., \\ Mexico; ecarvajal@ciad.mx \\ * Correspondence: rodriguez_felix_fco@hotmail.com
}

Received: 2 December 2019; Accepted: 23 December 2019; Published: 9 January 2020

\begin{abstract}
Stenocereus thurberi is an endemic species in northwestern Mexico. It produces colorful fruits called pitayas that have an edible pulp. They have phytochemical compounds associated with biological activities. Ultrafiltration is a widely used method for the clarification of fruit juices and the recovery of phytochemicals. However, its effect has not been extensively studied in extracts. Therefore, the objective of this work is to study the effect of the ultrafiltration of pitaya extract (Stenocereus thurberi) on its phytochemical content, antioxidant capacity, and identification of phenolic compounds by UPLC-DAD-MS, providing greater knowledge about the pitaya. In this study, two extracts were analyzed, the unclarified extract (UE) and the clarified extract (CE). The antioxidant capacity was higher in the CE with $15.93 \pm 0.42 \mathrm{mM} \mathrm{TE} / \mathrm{g}$, DPPH and $18.37 \pm 0.016 \mathrm{mM} \mathrm{TE} / \mathrm{g}$, ABTS. The UPLC-MS analysis indicated the decrease in phenolic compounds in the CE and the presence of gallic acid and resorcinol, compounds that had not been identified in other species of Stenocereus spp. The correlation analysis indicated that all the phytochemicals present in the pitaya contribute significantly to the antioxidant capacity. The ultrafiltration process could be a viable option to improve the biological activity of the natural extracts.
\end{abstract}

Keywords: pitaya; Stenocereus thurberi; phytochemical; antioxidant capacity; ultrafiltration; UPLC-DAD-MS

\section{Introduction}

The columnar cactus Stenocereus thurberi is an endemic species in the northwest of Mexico and is little known compared to other species such as Stenocereus queretaroensis, Stenocereus pruinosus, and Stenocereus stellatus [1]. This genus produces prickly, spherical, or ovoid fruits commonly called pitayas, its flesh edible and of different colors which vary in shades of yellow, orange, red, and purple due to the presence of betalains [2].

Betalains are water-soluble nitrogenous pigments, and are synthesized from the amino acid tyrosine into two structural groups: betacyanins that represent a red-violet coloration, and betaxanthins with yellow-orange coloration [3]. These pigments present diverse biological activities, among which 
stand out are their anti-inflammatory, anticancer, and antioxidant properties [4]. The antioxidant activity of betalains is derived from the presence of betalamic acid, which is an aromatic amino compound capable of stabilizing free radicals. This stabilization is closely related to its ability to donate electrons [5]. Another important group of phytochemicals found in pitaya pulp are phenolic compounds, which, like betalains, have been associated with biological activities, which are attributed to the phenolic hydroxyl groups that are $\mathrm{H}$-donor antioxidants eliminating reactive species. In this way phenolic compounds can inhibit the oxidation of lipids, proteins, DNA, and enzymes involved in the generation of radicals that are associated with chronic degenerative diseases, so we can say that these phytochemicals play an important role in nutrition and human health. [1]. Nowadays, the recovery of biologically active phytochemicals from natural sources has generated great interest due to its potential use as ingredients in food products, pharmaceuticals, and cosmetic formulations [6].

Ultrafiltration is a physical method of recovery and separation of compounds as of a feed solution under applied hydrostatic pressure, so the feed solution is divided into a permeate fraction containing all the compounds that permeate the membrane and a retention fraction that did not permeate the membrane. The process does not involve temperature, does not apply phase changes or chemical agents, and is characterized by high efficiency, low energy consumption, and simple equipment. For this reason, ultrafiltration is one of the most used methods in the food industry, mainly for the clarification of fruit juices and the collection of bioactive compounds $[7,8]$. In the literature, there are studies on the use of membranes for the extraction and separation of bioactive compounds from various natural extracts [9-13]. However, there are few studies on the effect of ultrafiltration on cacti fruit extracts, and research does not specify the molecules that are involved before and after the process [7,14-16]. Thus, a better understanding of the effect of ultrafiltration requires the use of chromatographic tools such as UPLC-DAD-MS to help explain why certain ultrafiltrated extracts are benefited or impaired in their biological activity. The objectives of this work are to study the effect of the ultrafiltration of pitaya extract (Stenocereus thurberi) on its phytochemical content, antioxidant capacity, and identification of phenolic compounds by UPLC-DAD-MS, as well as to provide greater knowledge on the processing of pitaya extract, given that it is a little known and valued source.

\section{Results and Discussion}

\subsection{Physico-Chemical Characterization}

Figure 1 shows the physical and chemical characteristics of the red pitaya of $S$. thurberi. The morphological attributes of the fruit show an almost spherical shape with polar and longitudinal diameters larger than those reported for S. pruinosus, S. stellatus, and S. griseus; however, the fruit of $S$. thurberi presented less weight compared to the fruits of the species mentioned above, ranging from $171.15 \mathrm{~g}$ to $91.26 \mathrm{~g}$. The differences in weight between the fruits of these species are due to their high perspiration rate and the number of areolas, since the thorns present in the areolas help to reduce water loss [2]. Transpiration is one of the causes of post-harvest losses of this fruit and is classified as a phenomenon of water transport from the inside of the fruit to the outside, through plant structures such as the epidermis [17]. Regarding its chemical attributes, the amount of total sugars was similar to that reported for S. pruinosus (57.1-66.7 mg/g), S. stellatus (60.7-68.6 mg/g), and 'S. griseus (76.0-103.0 mg/g) [2,18], suggesting that such content could be a characteristic feature of the Stenocereus genus [18]. The titratable acid value of the red pitaya $S$. thurberi was similar to that reported for S. pruinosus $(0.17 \%)$ and S. griseus $(0.18 \%)$, while in S. stellatus are reported values of $0.60 \%$, consistently the $\mathrm{pH}$ value was similar to that reported for S. pruinosus (5.70), while for $S$. stellatus, values of 4.19 are reported [2], suggesting that pitaya fruit $S$. thurberi is sweeter that fruit $S$. stellatus. In terms of the color attributes of the red pulp of $S$. thurberi, values of $29.45^{\circ}$ were obtained for the hue angle, 36.29 for chroma, and $17.19 \%$ for luminosity. Comparing these results with what was reported by García et al. [19] where they evaluated the color for the red pulp of S. pruinosus $\left(\mathrm{L}^{*}=19.4 \%, \mathrm{H}^{*}=19.8^{\circ}\right.$ and $\left.C^{*}=24.7\right), S$. thurberi it has a red-orange hue, while $S$. pruinosus has a magenta hue. The color 
of the pitaya fruit is derived from the presence of betalains [20], whereby the color is an indicator of the proportion between the two different groups (betacyanins and betaxanthins); therefore, it can be assumed that pulp of $S$. pruinosus has a higher betacyanins content than betaxanthins, while in the pulp of $S$. thurberi, the proportion could be very similar between both groups.

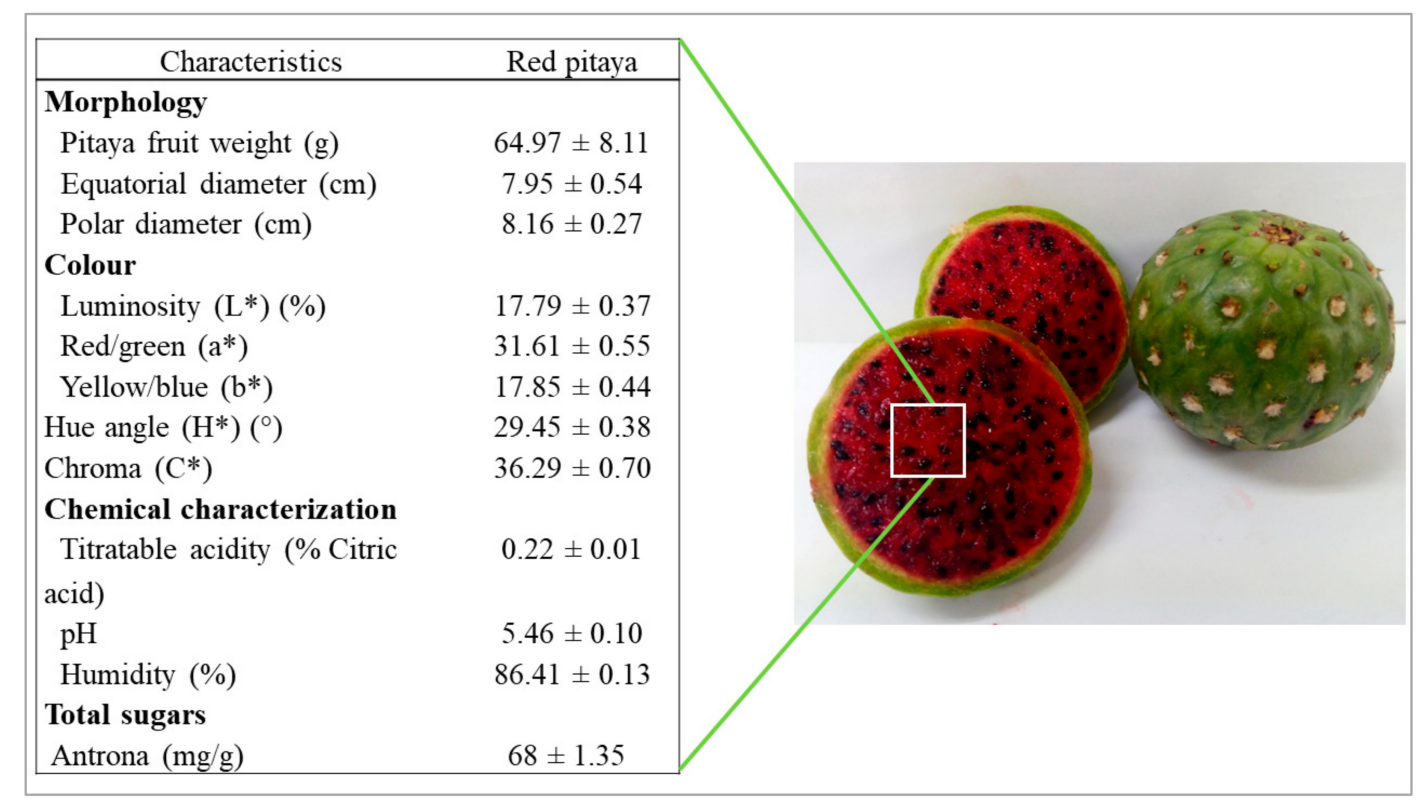

Figure 1. Physical-chemical composition of pitaya pulp (Stenocereus thurberi).

\subsection{Phytochemical Content}

Table 1 shows the phytochemical content of the UE and CE of pitaya. The content of total phenols for the UE was similar to that reported for the fruits of other cactaceae such as garambullo (Myrtillocactus geometrizans) with values of 7.4 to $10.02 \mathrm{mg} \mathrm{GAE} / \mathrm{g}$ [21] and Cuaresmeño xoconostle (Opuntia matudae) with $8.5 \mathrm{mg} \mathrm{GAE} / \mathrm{g}$ [22]. However, for other genera and species of cactus such as O. stricta, O. undulara, and O. ficus indica, lower values of 1.64 to $2.18 \mathrm{mg}$ GAE/g have been reported [23,24]. García et al. [2], reported the total phenolic content of the S. pruinosus and S. stellatus of red, orange, and white pitaya pulp with values of $0.35-0.70 \mathrm{mg}$ GAE/g mentioning that the red variety was the one that presented the value higher. While in the pitaya pulp S. griseus was $1.66 \mathrm{mg} \mathrm{GAE} / \mathrm{g}$ [19]. The content of phenols is variable among the fruits of cactaceaes, even of the same genus, showing greater content in the red pulp of pitaya $S$. thurberi, studied by us. However, these data could be overestimated, because the colorimetric method used in its determination is not specific for phenols, and other compounds such as sugars and vitamin C can reduce the Folin-Ciocalteu reagent [25], which can be confirmed with the total sugar values mentioned above and titratable acidity. The total phenolic content showed significant differences $(p<0.05)$ between the analyzed extracts, with $13.89 \pm 0.75$ and $20.70 \pm 0.81 \mathrm{mg}$ GAE/g in UE and CE, respectively, a result consistent with those reported by Vergara et al. [26] where they physicochemically evaluated the ultrafiltered and unfiltered extract of the prickly pear (O. ficus indica), finding significant differences in the quantification of phenols in both extracts. Ultrafiltration is a method of separation of molecules, and in its use in the fruit extracts of cacti, it has been observed that molecules such as polysaccharides, proteins, and sugars are diminished; incidentally this result may be due to the greater availability of reactive groups that can reduce reagent Folin-Ciocalteu, contributing to a greater quantification of phenols [26,27]. 
Table 1. Phytochemical content in the clarified and uncleared extract of pitaya (Stenocereus thurberi).

\begin{tabular}{|c|c|c|c|}
\hline \multicolumn{2}{|c|}{ Phytochemical } & UE & $\mathrm{CE}$ \\
\hline \multicolumn{2}{|c|}{ Phenols (mg GAE/g) } & $13.89 \pm 0.75^{a}$ & $20.70 \pm 0.81^{b}$ \\
\hline \multirow{2}{*}{ Betalains (mg/g) } & Betacyanins & $0.94 \pm 0.15^{\mathrm{a}}$ & $1.17 \pm 0.27^{\mathrm{a}}$ \\
\hline & Betaxanthins & $1.16 \pm 0.30^{\mathrm{a}}$ & $1.37 \pm 0.41^{\mathrm{a}}$ \\
\hline
\end{tabular}

${ }^{*}$ Different letters mean significant differences $(p<0.05)$.

The content of betacyanins and betaxanthins was higher compared to prickly pear (O. ficus indica) where for betacyanins it ranges from 0.07 to $0.254 \mathrm{mg} / \mathrm{g}$ and betaxanthins 0.12 to $0.88 \mathrm{mg} / \mathrm{g}[26,28]$. In pitayas of species such as S. pruinosus and S. stellatus, betalain values of $0.535 \mathrm{mg} / \mathrm{g}$ and $0.707 \mathrm{mg} / \mathrm{g}$, respectively, have been reported [2]. Pérez et al. [29] analyzed the betalains content in Stenocereus stellatus pitayas and compared it with 32 samples of other cactus fruits in order to classify cactus fruits as poor, good, and excellent sources of betalains They calculated three confidence intervals for the total betalain

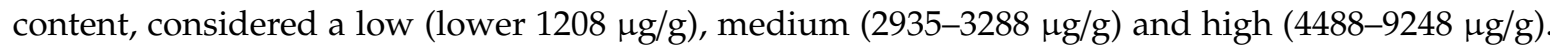
Considering this classification, the betalains content in the pitaya pulp Stenocereus thurberi is defined as a good source of betalains. The beet (Beta vulgaris) has a betalains content of $39.76 \mathrm{mg} / \mathrm{g}$, well above the values obtained with respect to other sources [30]. However, pitaya fruits have higher concentrations of betalains compared to other cactaceae. On the other hand, the betalains content in both extracts did not show significant differences. These results are consistent with those reported by Castro et al. [27] and Vergara et al. [26], who evaluated the physicochemical characteristics of the ultrafiltered extract of the prickly pear (O. ficus indica) where they found no significant differences in betalains content between both extracts. The slight decrease in betalains in the UE is due to the turbidity caused mainly by the presence of polysaccharides causing an increase in color intensity [27].

\subsection{Antiradical Capacity $A B T S^{+}$and $D P P H$}

Figure 2a,b shows the antioxidant capacity of UE and CE by the DPPH and ABTS methods expressed in \% inhibition and $\mathrm{mM} \mathrm{TE} / \mathrm{g}$ of dry samples. We can observe that both extracts showed great antioxidant capacity, comparing these results with other cactaceous fruits. García et al. [2] evaluated by ABTS the antioxidant capacity of the pitaya pulp (S. pruinosus and S. stellatus) of different colors: red (Spr, Ssr), orange (Spo), and white (Ssw), respectively. They mention that the red pitayas for both species had the highest antioxidant capacity with values for Spr $4.91 \pm 0.20 \mathrm{mM} \mathrm{TE} / \mathrm{Kg}$ and Ssr $6.68 \pm 072 \mathrm{mM} \mathrm{TE} / \mathrm{Kg}$ of dry samples. Another of the fruits of cacti that have been evaluated by ABTS is the prickly pear (Opuntia ficus-indica), which shows an antioxidant capacity in a range of $0.0337-0.0856 \mathrm{mM} \mathrm{TE} / \mathrm{g}$ of fresh samples [31,32]. In the red pitaya (Hylocereus polyrhizus) the antioxidant capacity with the DPPH radical was also determined, the value obtained being $0.001664 \mathrm{mM} \mathrm{TE} / \mathrm{g}$ [33]. These results may be due to the presence of phenolic compounds and betalains capable of reducing DPPH and ABTS radicals. The identification of phytochemicals of the genus Stenocereus spp from two species S. pruinosus and S. stellatus has been reported in the literature. García et al. [1] reported that the profiles and concentrations of betalains and phenolic compounds in the fruits of the two Stenocereus species studied, varied according to the color of the pulp and among the species. In addition, in the red varieties, betalains were present at much higher levels than the phenolic compounds. Betalains are molecules with a high antioxidant capacity comparable to epicatechin gallate, capable of donating electrons and protons due to the presence of a 5-O-glucosyl catechol and 1,7-diazaheptamethinium [34]. However, not all betalains have the same antioxidant capacity, and this will depend on the source and position of the hydroxyl/imino groups and the glycosylation of aglycone in the betalains structure [35]. 
a)

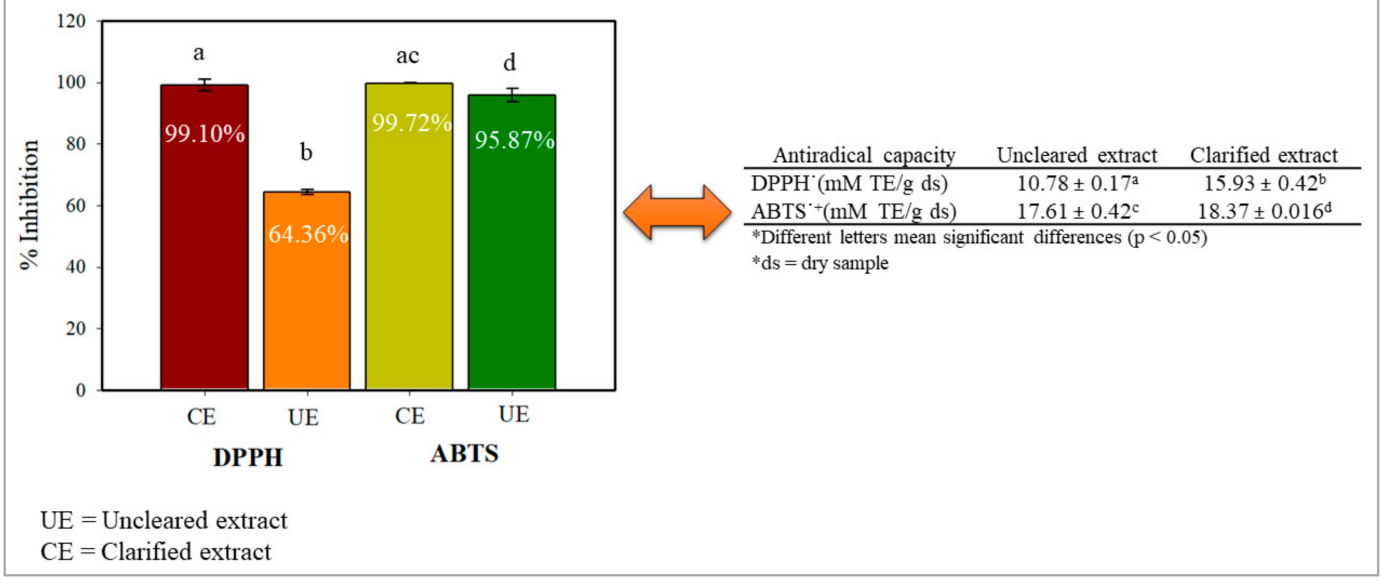

Figure 2. Antiradical capacity ABTS ${ }^{+}$and $\mathrm{DPPH}^{\cdot}$ (a) presented in percent inhibition and (b) in Trolox equivalents of the UE and CE of pitaya (Stenocereus thurberi).

On the other hand, the antioxidant capacity was significantly different between the extracts and in both radicals. These results are consistent with those reported by Castro et al. [7] where antioxidant capacity values are favored by ultrafiltering the extract, they obtained values of the unfiltered extract of $11.48 \mu \mathrm{M} \mathrm{TE} / \mathrm{g}$ and ultrafiltrate $15.09 \mu \mathrm{M}$ TE/g in the prickly pear extract (Opuntia ficus-indica). In the literature, it has been reported that the purified extracts the potential of its functional properties was increased. Tenore et al. [36] evaluated the complete and purified extracts of pitaya (Hylocereus polyrhizus) in microorganisms and they mentioned according to the values of the minimum inhibitory concentration (MIC) that the purified extracts of both pulp and shell exerted a broad antimicrobial spectrum by inhibiting the growth of all bacteria, while whole extracts revealed very low activity or were totally inactive. Therefore, these results could be due to the permeate and concentration of highly antioxidant compounds present in the CE and in the UE may contain compounds that could act as prooxidants avoiding the reduction of radicals since it has been seen that with the ultrafiltration method there may be a retention of compounds in the membrane of up to $50 \%[14,37,38]$.

Table 2 shows the values of the concentration at which $50 \%$ of the reduction of ABTS and DPPH radicals is had. We can observe that the $\mathrm{CE}$ was the one that presented significantly lower values of IC 50 with respect to the UE. Luo et al. [39] reported IC50 values in the DPPH radical of $0.83 \mathrm{mg} / \mathrm{mL}$ for the Hylocereus polyrhizus pitahaya shell. However, the values obtained in the ABTS radical for CE are similar to those obtained for ascorbic acid with an IC50 of $1.81 \mathrm{mg} / \mathrm{mL}$, which is a potent antioxidant [40]. The significant difference between the ABTS and DPPH radicals in both extracts may be due to the fact that the mechanism of inhibition used by both extracts is by hydrogen atom transfer (HAT) because of the inhibition of the ABTS radical predominates. However, this may be due to several factors such as solubility, link dissociation energy, ionization potential, antioxidant structure, and solvent [41].

Table 2. Values necessary to inhibit $50 \%$ of the DPPH' and ABTS ${ }^{+}$radical of the uncleared extract and clarified extract.

\begin{tabular}{lccc}
\hline & & Uncleared Extract & Clarified Extract \\
\cline { 2 - 4 } $\mathrm{IC}_{50}(\mathrm{mg} / \mathrm{mL})$ & DPPH $^{-}$ & $8.9^{\mathrm{a}}$ & $5.6^{\mathrm{c}}$ \\
& ABTS $^{+}$ & $3.0^{\mathrm{b}}$ & $1.8^{\mathrm{d}}$ \\
\hline
\end{tabular}

${ }^{*}$ Different letters mean significant differences $(p<0.05)$. 


\subsection{Identification of Phenolic Compounds by UPLC-DAD-MS}

Table 3 shows the results of the MS analysis with the possible compounds that are present in the samples. We can observe that in the UE there was a greater presence of phenolic compounds such as ferulic acid, caffeic acid, p-coumaric acid and quercetin with retention times of 0.43, 2.45, 4.19 , and $9.23 \mathrm{~min}$, respectively (Figure 3a). The presence of these phenolic compounds has also been reported by Garcia et al. [1] in the pitaya pulp of Stenocereus stellatus and Stenocereus pruinosus. However, in the CE there is a decrease in phenolic compounds (Figure 3b), mainly those that have the longest retention time such as caffeic acid, rutin, quercetin, and isorhamnetin to mention a few. This result can be related to the recovery factor of the ultrafiltration process where $50 \% \pm 0.066$ was obtained. Some researchers have studied the effect of ultrafiltration as reported by Pap et al. [40] who studied the effect of ultrafiltration on the content of anthocyanins and flavonoids in blackcurrant juice, the authors mention that the ultrafiltration process had a significant effect on the $50 \%$ decrease of these compounds compared to the initial juice. Also, Cassano et al. [42] observed that the decrease of phenolic compounds in the tangerine game, as well as the decrease of flavonoids in prickly pear juice [14]. This decrease is mainly due to the pore size of the ultrafiltration membrane to one that is not the only reason, but also to the phenomenon of membrane fouling, such as pore blockage and the formation of compound layers, which promote retention of compounds in the membrane [38]. In Figure 4, the ultrafiltration process is schematized, where it can be seen that the EC has a decrease in molecules. However, despite the decrease in phenolic compounds due to ultrafiltration in the CE, this extract showed a greater antioxidant capacity in both radicals. This indicates that in purified extracts functional properties can be favored, due to concentration, and that many compounds can act antagonistically or synergistically $[36,43]$.

Table 3. Identification of possible phytochemicals present in the pitaya pulp (Stenocereus thurberi) of the UE and CE.

\begin{tabular}{|c|c|c|c|c|c|c|c|c|}
\hline Peak & & Chemical Structure & MF & MM & $m / z(\mathbf{M}+\mathbf{H})^{+}$ & $m / z$ (M-H) $^{-}$ & UE (Rt) & CE (Rt) \\
\hline & Phenolic compounds & & & & & & & \\
\hline 1 & Ferulic acid & & $\mathrm{C}_{10} \mathrm{H}_{10} \mathrm{O}_{4}$ & 381 & 382 & 380 & 0.43 & 0.45 \\
\hline 2 & Gallic acid & & $\mathrm{C}_{7} \mathrm{H}_{6} \mathrm{O}_{5}$ & 170 & 171 & 169 & 0.56 & 0.56 \\
\hline 3 & Resorcinol & & $\mathrm{C}_{6} \mathrm{H}_{6} \mathrm{O}_{2}$ & 110 & 111 & N.D. & 1.15 & 1.15 \\
\hline 4 & Catechin & & $\mathrm{C}_{15} \mathrm{H}_{14} \mathrm{O}_{6}$ & 290 & 291 & 289 & 1.21 & 1.25 \\
\hline 5 & Caffeic acid & & $\mathrm{C}_{9} \mathrm{H}_{8} \mathrm{O}_{4}$ & 180 & 181 & N.D. & 2.45 & N.D. \\
\hline 6 & p-coumaric acid & & $\mathrm{C}_{9} \mathrm{H}_{8} \mathrm{O}_{3}$ & 164 & 165 & 163 & 4.19 & 4.19 \\
\hline 7 & Rutin & & $\mathrm{C}_{27} \mathrm{H}_{30} \mathrm{O}_{16}$ & 610 & 611 & 609 & 6.52 & N.D. \\
\hline 8 & Isorhamnetin & & $\mathrm{C}_{16} \mathrm{H}_{12} \mathrm{O}_{7}$ & 316 & 317 & N.D. & 8.14 & N.D. \\
\hline 9 & Quercetin & & $\mathrm{C}_{15} \mathrm{H}_{10} \mathrm{O}_{7}$ & 302 & 303 & N.D. & 9.23 & N.D. \\
\hline 10 & Caffeoylquinic acid & & $\mathrm{C}_{16} \mathrm{H}_{18} \mathrm{O}_{9}$ & 354 & N.D. & 353 & 11.31 & N.D. \\
\hline 11 & Glycosylated quercetin & & $\mathrm{C}_{21} \mathrm{H}_{20} \mathrm{O}_{12}$ & 464 & 465 & N.D. & 11.90 & N.D. \\
\hline
\end{tabular}

N.D. = Not detected; RT = Retention time; MF = Molecular formula; MM = Molecular mass; $m / z=$ mass $/$ charge. 

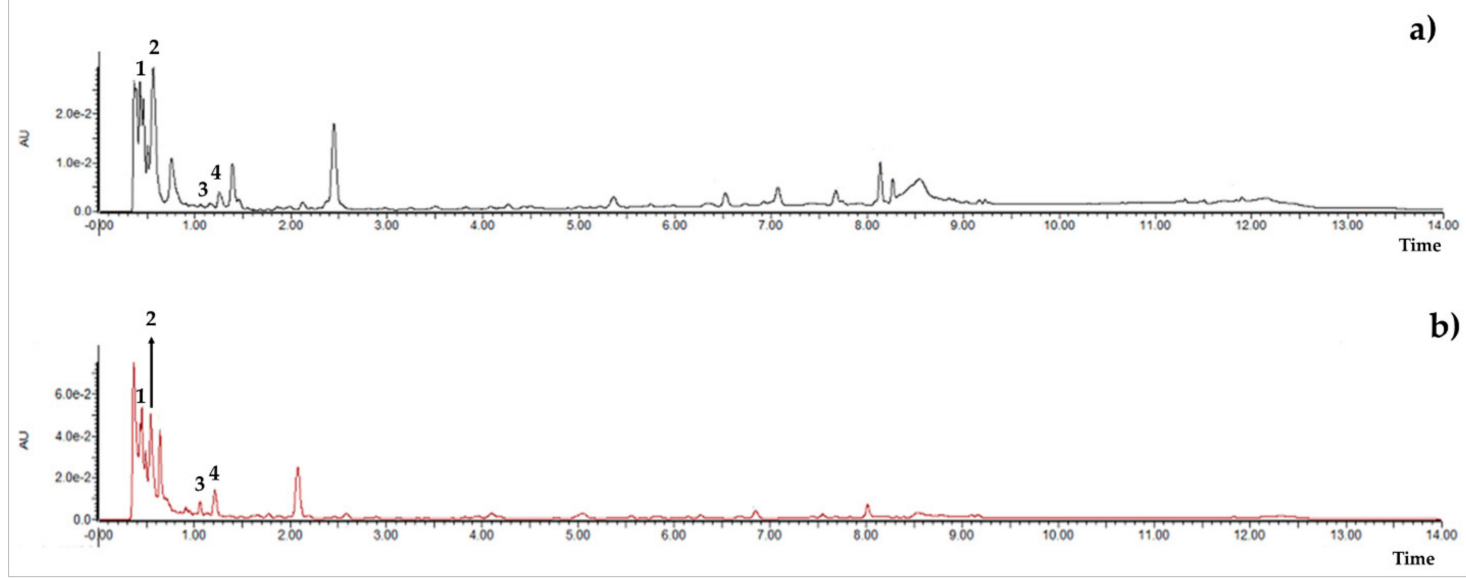

b)

Figure 3. UPLC chromatograms of the phenolic compounds present in the uncleared extract (a) and clarified (b) at $280 \mathrm{~nm}$, [y axis = intensity (absorbance unit, AU); $x$ axis = retention time (min)]. Peaks: 1, ferulic acid; 2, gallic acid; 3, resorcinol and 4, catechin.

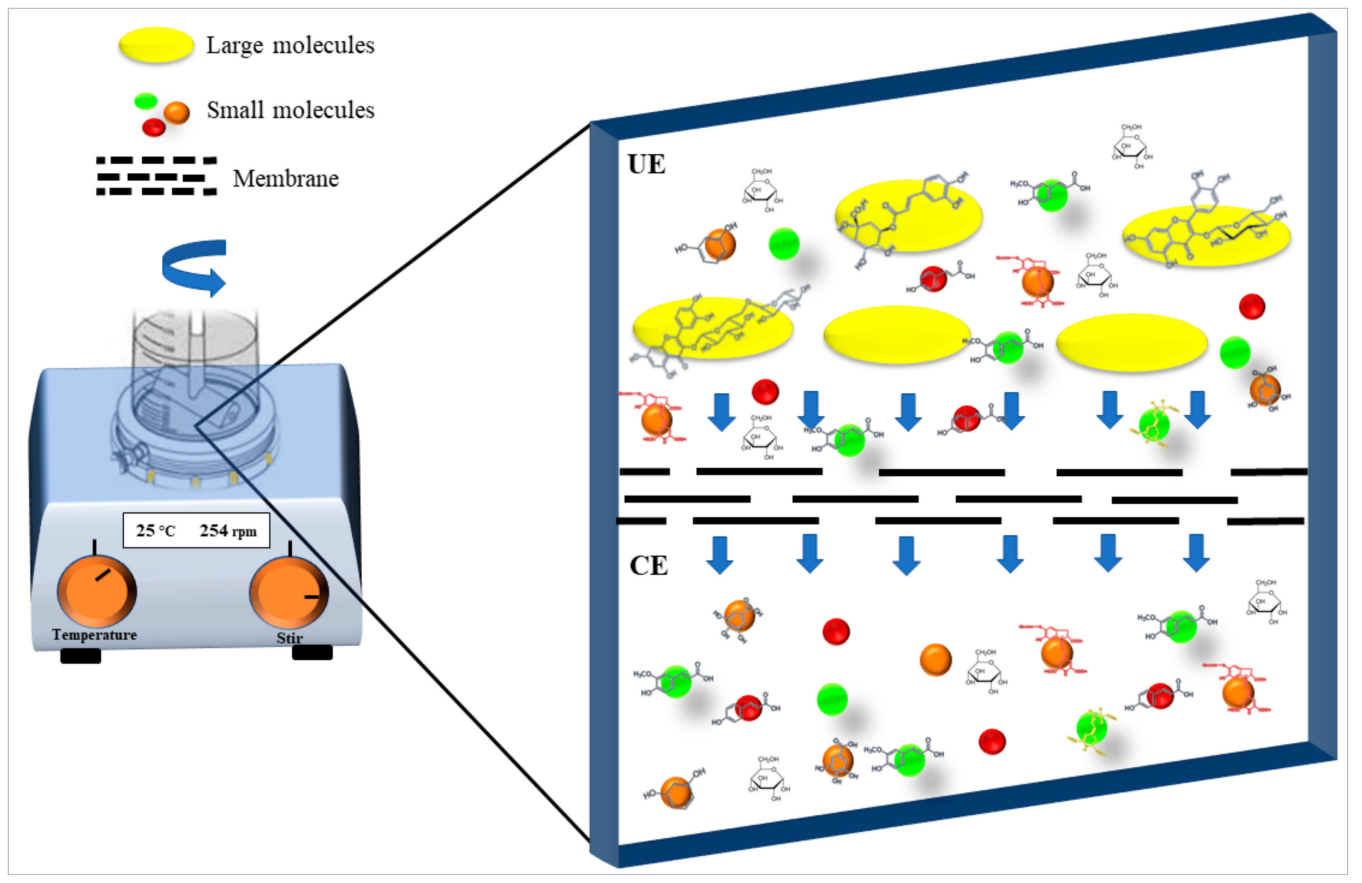

Figure 4. Scheme of the ultrafiltration process representing the main molecules present in the pitaya extract (Stenocereus thurberi) before and after the process.

In both studied extracts of pitaya pulp (Stenocereus thurberi), the presence of gallic acid and resorcinol was identified at $0.56 \mathrm{~min}$ and $1.15 \mathrm{~min}$, respectively (Table 3 and Figure 3a,b). It is our knowledge that such compounds have not been reported in the genus of Stenocereus spp. It is clear that there are few studies on the species of this genus and its fruits. Therefore, this finding could provide added value to the pitaya Stenocereus thurberi, since gallic acid has properties such as antimutagenic, antifungal, and is a potent antioxidant even more effective than ascorbic acid [44,45]. Similarly, resorcinol is a phenolic compound widely used in cosmetics, medications, and as an antioxidant [46].

\subsection{Correlation Analysis between Phytochemicals and Antioxidant Capacity}

In Table 4 we can observe the correlation coefficient values between the antioxidant capacity and the phytochemical content of the pitaya (Stenocereus thurberi). The correlation coefficients between antioxidant capacity and total phenolic content were positive and highly significant $(p \leq 0.01)$ for the 
DPPH radical and significant $(p<0.05)$ for the ABTS radical in both samples. This observation is consistent with the work of Dehbi et al. [47] regarding the correlation of the total phenolic content with the antioxidant capacity in juices of nine prickly pear cultivars (Opuntia ficus-indica).

Table 4. Values of correlation coefficients between antioxidant capacity (ABTS, DPPH) and the phytochemical content of the Uncleared extract and Clarified extract of pitaya (Stenocereus thurberi).

\begin{tabular}{|c|c|c|c|c|c|}
\hline \multirow{3}{*}{\multicolumn{2}{|c|}{ Phytochemical }} & \multicolumn{4}{|c|}{ Coeficientes de Correlación (r) } \\
\hline & & \multicolumn{2}{|c|}{ UE } & \multicolumn{2}{|c|}{$\mathrm{CE}$} \\
\hline & & * ABTS & * DPPH & * ABTS & ${ }^{*} \mathrm{DPPH}$ \\
\hline \multicolumn{2}{|c|}{ Phenolic compounds } & 0.983 & 0.997 & 0.922 & 0.988 \\
\hline \multirow{2}{*}{ Betalains } & Betacyanins & 0.982 & 0.992 & 0.902 & 0.997 \\
\hline & Betaxanthins & 0.991 & 0.994 & 0.941 & 0.991 \\
\hline
\end{tabular}

${ }^{*}$ All data were significant $(p<0.05)$.

The antioxidant capacity of phenolic compounds is attributed to their redox properties, which allow them to act as reducing agents, hydrogen donors, oxygen inhibitors, and metal chelation [48]. The correlation coefficients between antioxidant capacity and betacyanins and betaxanthins content were greater than $0.90(r>0.90)$ in all cases. The betacyanins and betaxanthins content of the pitaya was positively correlated with the antioxidant capacity and highly significant $(p \leq 0.01)$ for both radicals and samples, respectively. It has been reported that the antioxidant activity of betalains is related to its chemical structure since the antioxidant capacity increases with the number of hydroxyl groups and imino groups and decreases with higher glycosylation in the molecule [49]. However, according to Gandía et al. [50], the antioxidant activity of betalains, in particular betaxanthins, is not related to the presence of hydroxyl groups or aromaticity of the structure. According to the same authors, there is an "intrinsic activity" of betaxanthins that could be associated with the resonance system that is supported by the two nitrogen atoms and be general for all betalains. However, the presence of hydroxyl groups in betaxanthins increases their antioxidant capacity [50]. Therefore, these data suggest that phenolic compounds such as betacyanins and betaxanthins present in pitaya (Stenocereus thurberi) contribute significantly to antioxidant capacity.

\section{Materials and Methods}

\subsection{Raw Material}

Pitaya fruits (S. thurberi) were randomly collected in the months of June-July 2016 in the township of Carbó, located to the west of the state of Sonora, Mexico between the geographical coordinates $29^{\circ}$ $41^{\prime}$ north latitude, and $110^{\circ} 57^{\prime}$ west longitude.

\subsection{Reagents}

The reagents used were ethanol (CTR, Monterrey, MX), methanol (Meyer, Monterrey, MX), 2, 2-Diphenyl-1-picrylhydrazyl (DPPH) (Sigma-aldrich, St. Louis, MO, USA), 2,2-azino-bis(3-ethylbenzothiazoline-6-sulfonic acid) (ABTS) (Sigma-aldrich, Oakville, CA), Folin-Ciocalteu's phenol (Sigma-aldrich, St. Louis, MO, USA), trolox 6-hydroxy-2,5,7,8-tetramethylchromane-2-carboxylic acid (Sigma-aldrich, Steinheim, DE), gallic acid (Sigma-aldrich, Hong Kong, CN).

\subsection{Physico-Chemical Characterization}

Equatorial and polar diameters were evaluated with a Vernier gauge. Color was evaluated with a Hunter Lab colorimeter (Mini Scan XE Plus, Reston, Virginia, USA) and was expressed in hue angle $\left(\mathrm{H}^{*}\right)$, chroma $\left(\mathrm{C}^{*}\right)$, luminosity $\left(\mathrm{L}^{*}\right)$, $\mathrm{a}^{*}$ (verde/rojo) y b* (azul/amarillo). The $\mathrm{pH}$ was measured with 
potentiometer (Hanna, HI 2550), it was performed by weighing $1 \mathrm{~g}$ of pitaya pulp without seeds and $10 \mathrm{~mL}$ of milli-Q water was added (AOAC 981.12) [51]. Acidity was assessed by titration with $\mathrm{NaOH}$ $0.1 \mathrm{~N}$, performed by the weighing of $1 \mathrm{~g}$ of seedless pulp; $30 \mathrm{~mL}$ of mili-Q water was added, the solution was vigorously stirred, and subsequently the sample was titrated (AOAC 935.57) [51]. Total sugar content was evaluated with the method of antrona following the modified methodology of Laurentin and Edwards [52].

\subsection{Preparation of Uncleared Extract and Clarified Extract from S. thurberi Fruits}

Pitya fruits were washed and frozen at $-20^{\circ} \mathrm{C}$ for later use. The amount of $2 \mathrm{~g}$ of seedless pulp were macerated in $34 \mathrm{~mL}$ of distilled water. The mixture was placed in a water bath and subsequently sonicated (Branson, M3800H, Mexico city, MX) for $27 \mathrm{~min}$ and stirred for $20 \mathrm{~min}$ on a horizontal shaker (VWR, mini blot mixer, US) in the dark. Subsequently, the samples were centrifuged (Eppendorf, $5804 \mathrm{R}$, Hamburgo, DE) at $5000 \mathrm{rpm}$ for $10 \mathrm{~min}$. The supernatant obtained was lyophilized and stored in amber colored vials for later analysis. This sample corresponds to the uncleared extract (UE).

For obtaining the clarified extract (CE), $15 \mathrm{~mL}$ of UE was used and passed through the ultrafiltration process. They were placed in the Amicon stirred cell with a capacity of $50 \mathrm{~mL}$ (Millipore, model 8050, Darmstadt, DE) using membranes (Millipore, Temecula, USA) with a $1 \mathrm{kDa}$ molecular weight cutoff at $25{ }^{\circ} \mathrm{C}$ and a pressure of $50 \mathrm{psi}$ of nitrogen gas (Figure 5). Subsequently, the CE was lyophilized and stored in amber colored vials for later analysis. For each sample, the analysis was performed in triplicate, and in each sample the membranes were washed with $10 \%(\mathrm{v} / \mathrm{v})$ ethanol and mili-Q water. The following equation was used to obtain the recovery factor of the ultrafiltration process:

$$
\mathrm{RF}=\left(\frac{\mathrm{CE}}{\mathrm{UE}}\right) \times 100
$$

where CE is clarified extract and UE is uncleared extract.

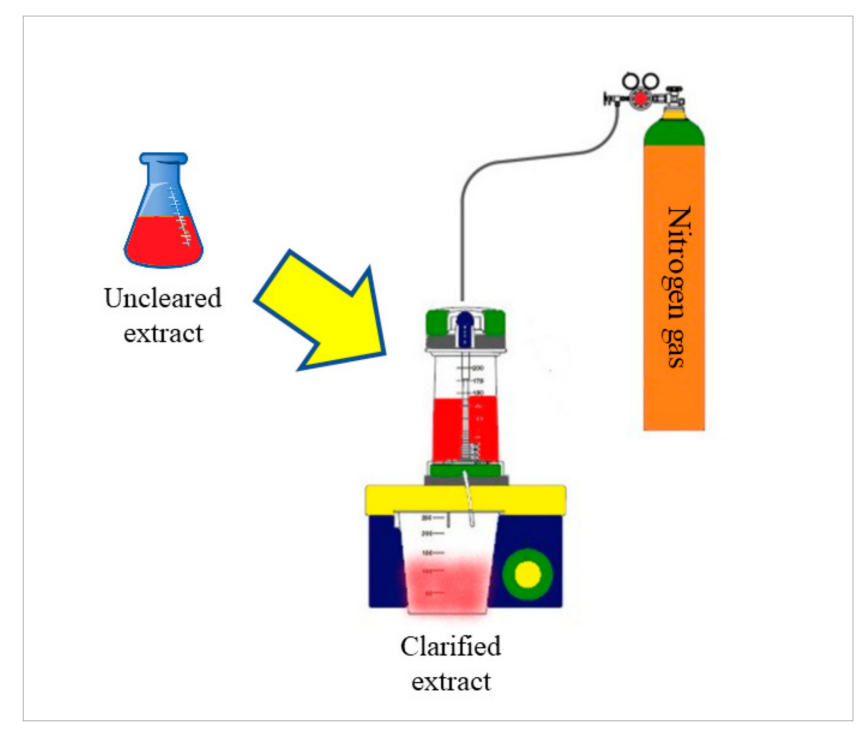

Figure 5. Ultrafiltration process to obtain the clarified extract.

\subsection{Photometric Quantification of Betalains}

The quantification of total betalains, betaxanthins, and betacyanins was carried out by measuring the absorbance at $538 \mathrm{~nm}$ for betacyanins and $483 \mathrm{~nm}$ for betaxanthins, using a UV-Vis spectrophotometer (Varian, Cary 50, Melbourne, AU). The amount of betalains was calculated by the following equation.

$$
\left[\mathbf{B}\left(\frac{\mathbf{m g}}{\mathrm{g}}\right)\right]=\frac{\mathbf{A} \times \mathbf{D F} \times \mathbf{M W} \times \mathbf{V}}{\varepsilon \times \mathbf{W} \times \mathbf{L}}
$$


where $[\mathrm{B}]$ means the betacyanins or betaxanthins concentration, $\mathrm{A}$ is absorbance of the sample, DF is dilution factor, MW is molecular weight (betanin $550 \mathrm{~g} / \mathrm{mol}$ ) (indicaxanthin $308 \mathrm{~g} / \mathrm{mol}$ ), $\mathrm{V}$ is volume, $\varepsilon$ is molar extinction coefficient, for betanin it is $60,000 \mathrm{~mol} / \mathrm{L} \times \mathrm{cm}$ and for indicaxanthin $48,000 \mathrm{~mol} / \mathrm{L} \times$ $\mathrm{cm}, \mathrm{W}$ is the weight of the sample $(\mathrm{g})$ and $\mathrm{L}$ is the length of the cuvette $(1 \mathrm{~cm})$. The total betalains was obtained with the sum of betacyanins and betaxanthins.

\subsection{Total Phenols}

Determination of total phenols was carried out with the Folin-Ciocalteu (FC) method, where $10 \mu \mathrm{L}$ of sample was mixed with $25 \mu \mathrm{L}$ of FC $1 \mathrm{~N}$ and allowed to stand 5 min. After, $25 \mu \mathrm{L}$ of $20 \% \mathrm{Na} 2 \mathrm{CO} 3$ and $140 \mu \mathrm{L}$ of distilled water were added. It was allowed to stand for $30 \mathrm{~min}$ and the absorbance at $760 \mathrm{~nm}$ was determined. The results were expressed as milligrams of gallic acid equivalents for gram of dry sample (mg GAE/g).

\subsection{Antiradical Capacity Using the ABTS + Assay}

The stabilization of the ABTS ${ }^{+}$radical was determined using the method of Re et al. [53]. It was $270 \mu \mathrm{L}$ of the radical solution with $20 \mu \mathrm{L}$ of sample was added and allowed to stand $30 \mathrm{~min}$ in the dark. Absorbance was measured at 734 on a microplate reader (Thermo scientific, Multiskan go, Vantaa, Finland).

\subsection{Antiradical Capacity Using the DPPH Assay}

The stabilization of the DPPH radical was performed based on the method proposed by Molyneux [54]. It was $200 \mu \mathrm{L}$ of radical with $20 \mu \mathrm{L}$ of sample was mixed and allowed to stand for $30 \mathrm{~min}$ in darkness. The absorbance was measured at $515 \mathrm{~nm}$ on a microplate reader (Thermo scientific, Multiskan go, Vantaa, Finland). The results were expressed for both radicals in mM TE/g and $\%$ inhibition according to the following equation:

$$
\% \text { inhibition }=\frac{A_{o}-\left(A_{\text {sample }}-A_{\text {blank sample }}\right)}{A_{o}} \times 100
$$

where: $A_{o}$ is absorbance of reagent $+\mathrm{H}_{2} \mathrm{O}, A_{\text {sample }}$ is absorbance of reagent + sample, $A_{\text {blank sample }}$ is absorbance of $\mathrm{H}_{2} \mathrm{O}+$ sample. From the $\%$ inhibition, the $\mathrm{IC}_{50}$ was obtained.

\subsection{Identification of Phenolic Compounds by UPLC-DAD-MS}

The identification of the phenolic compounds of the extracts of the pitaya pulp was made from a Waters UPLC analytical system (Waters, ACQUITY. Singapore) equipped with a diode array detector coupled to a mass spectrometer. For the analysis of the samples, a C18 column of $1.7 \mu \mathrm{m}(2.1 \times 50 \mathrm{~mm})$ (ACQUITY, UPLC BEH) was used. The gradients used were $0.1 \%$ acetic acid in deionized water (A), methanol (B), and acetonitrile (C). An isocratic gradient of 90\% (A), 5\% (B) and 5\% (C) was applied for $5 \mathrm{~min}$, and then it was $78 \%$ (A), $11 \%(\mathrm{~B})$, and $11 \%$ (C) for $5 \mathrm{~min}, 1 \mathrm{~min}$ of $36 \%(\mathrm{~A}), 31 \%$ (B) and $31 \%$ (C), and at the end a gradient of $90 \%$ (A), $5 \%$ (B) and $5 \%$ (C) was used for $2 \mathrm{~min}$. The flow rate was $0.3 \mathrm{~mL} / \mathrm{min}$, the column and sample temperatures were maintained at $35^{\circ} \mathrm{C}$ and $20^{\circ} \mathrm{C}$. The injection volume of the sample was $5 \mu \mathrm{L}$, and the absorbance was monitored at $280 \mathrm{~nm}$.

Electrospray ionization (ESI) was operated in positive and negative ion modes. The mass spectra were obtained in a range of $100-750 \mathrm{~m} / \mathrm{z}$, the capillary voltage was $3.00 \mathrm{kV}$ and a cone voltage of $30 \mathrm{~V}$. The ESI-MS parameters were a desolvation temperature of $400{ }^{\circ} \mathrm{C}$ and a gas flow of $650 \mathrm{~L} / \mathrm{h}$. The identification of phenolic compounds was based on standards, $m / z$ values, and scientific articles.

\subsection{Statistical Analysis}

The results of three independent tests are reported as the mean value \pm standard deviation. Means were compared by analysis of variance and Tukey comparison test, with a significance level $(p<0.05)$. 
For the study of the degree of the linear relationship between the variables, the Pearson correlation coefficient was used. All the data were processed and analyzed in the InfoStat software by window version 2008 (InfoStat, Cordoba, Argentina).

\section{Conclusions}

The effect of ultrafiltration on phytochemical content, antioxidant capacity, and the profile of phenolic compounds in pitaya extract was studied. The content of phenolic compounds present in the pitaya extract Stenocereus thurberi was first identified by the UPLC-DAD-MS method. It was possible to identify gallic acid and resorcinol, compounds that have not been reported in other extracts of cacti. The use of the ultrafiltration method helped the separation, selection, and concentration of molecules, showing effects on antioxidant capacity, total phenolic content, and the profile of phenolic compounds. The ultrafiltration is a technology widely used at the industrial level that could help to potentiate the biological activity of natural extracts such as the pitaya (Stenocereus thurberi).

Author Contributions: D.D.C.-E. wrote the paper. B.M.-L. and C.L.D.T.-S. designed the experiments. C.G.B.-U. and J.A.T.-H. performed experimental work. J.E.J.-O. and E.C.-M. discussed and interpreted results. G.A.L.-A. and F.R.-F. reviewed and corrected the document. All authors have read and agreed to the published version of the manuscript.

Funding: This research was funded by CONACYT, basic science project number 285445.

Acknowledgments: The authors are grateful to the University of Sonora and to CONACYT for their support.

Conflicts of Interest: The authors declare no conflict of interest.

\section{References}

1. García, L.; Dueñas, M.; Santos, C.; Valle, S.; Salinas, Y. Betalains and phenolic compounds profiling and antioxidant capacity of pitaya (Stenocereus spp.) fruit from two species (S. Pruinosus and S. stellatus). Food Chem. 2017, 234, 111-118. [CrossRef] [PubMed]

2. García, L.; Valle, S.; Salinas, Y.; Luna, C. Postharvest quality, soluble phenols, betalains content, and antioxidant activity of Stenocereus pruinosus and Stenocereus stellatus fruit. Postharvest. Biol. Technol. 2016, 111, 69-76. [CrossRef]

3. Polturak, G.; Aharoni, A. “La Vie en Rose”: Biosynthesis, Sources, and Applications of Betalain Pigments. Mol. Plant 2018, 11, 7-22. [CrossRef]

4. Choo, W.S. Betalains: Application in Functional Foods. Bioact. Mol. Food 2017, 1-28.

5. Belhadj, S.I.; Najar, T.; Abderrabba, M. Chemical and antioxidant properties of betalains. J. Agric. Food Chem. 2017, 65, 675-689. [CrossRef] [PubMed]

6. Reis, M.H.M.; Madrona, G.S.; Ferreira, F.B.; de Santana Magalhães, F.; Bindes, M.M.M.; Cardoso, V.L. Membrane Filtration Processes for the Treatment of Nonalcoholic Beverages. In Engineering Tools in the Beverage Industry; Elsevier: Kidlington, UK, 2019; pp. 175-207.

7. Castro, R.; Barragán, B.E.; Yáñez, J. Use of gelatin-maltodextrin composite as an encapsulation support for clarified juice from purple cactus pear (Opuntia stricta). LWT-Food Sci. Technol. 2015, 62, 242-248. [CrossRef]

8. Mai, H.C. Application of Cross-Flow Filtration Technique in Purification and Concentration of Juice from Vietnamese Fruits. Beverages 2017, 3, 44. [CrossRef]

9. Loizzo, M.R.; Sicari, V.; Tundis, R.; Leporini, M.; Falco, T.; Calabrò, V. The Influence of Ultrafiltration of Citrus limon L. Burm. cv Femminello Comune Juice on Its Chemical Composition and Antioxidant and Hypoglycemic Properties. Antioxidants 2019, 8, 23. [CrossRef] [PubMed]

10. Makhlouf, I.; Krichen, F.; Mansour, R.B.; Mokni, A.; Sila, A.; Bougatef, A.; Blecker, C.; Attia, H.; Besbes, S. Ultrafiltration and thermal processing effects on Maillard reaction products and biological properties of date palm sap syrups (Phoenix dactylifera L.). Food Chem. 2018, 256, 397-404. [CrossRef]

11. Toker, R.; Karhan, M.; Tetik, N.; Turhan, I.; Oziyci, H.R. Effect of ultrafiltration and concentration processes on the physical and chemical composition of blood orange juice. J. Food Process. Preserv. 2014, 38, 1321-1329. [CrossRef] 
12. Conidi, C.; Cassano, A.; Caiazzo, F.; Drioli, E. Separation and purification of phenolic compounds from pomegranate juice by ultrafiltration and nanofiltration membranes. J. Food Eng. 2017, 195, 1-13. [CrossRef]

13. Tundis, R.; Loizzo, M.R.; Bonesi, M.; Sicari, V.; Ursino, C.; Manfredi, I.; Conidi, C.; Figoli, A.; Cassano, A. Concentration of bioactive compounds from elderberry (Sambucus nigra L.) juice by nanofiltration membranes. Plant Foods Hum. Nutr. 2018, 73, 336-343. [CrossRef] [PubMed]

14. Cassano, A.; Conidi, C.; Drioli, E. Physico-chemical parameters of cactus pear (Opuntia ficus-indica) juice clarified by microfiltration and ultrafiltration processes. Desalination 2010, 250, 1101-1104. [CrossRef]

15. Cassano, A.; Conidi, C.; Timpone, R.; D'avella, M.; Drioli, E. A membrane-based process for the clarification and the concentration of the cactus pear juice. J. Food Eng. 2007, 80, 914-921. [CrossRef]

16. Castro-Muñoz, R.; Fíla, V.; Barragán-Huerta, B.E.; Yáñez-Fernández, J.; Piña-Rosas, J.A.; Arboleda-Mejía, J. Processing of Xoconostle fruit (Opuntia joconostle) juice for improving its commercialization using membrane filtration. J. Food Process. Pres. 2018, 42, e13394. [CrossRef]

17. Maguire, K.M.; Banks, N.H.; Opara, L.U. Factors affecting weight loss of apples. Hortic. Rev. 2001, 25, 197-234.

18. Yáñez, L.; Domínguez, J.; Fajardo, M.C.; Malpica, F.; Soriano, J.; Pelayo, C.; Armella, M.A.; Diaz-de-Leon, F. Quality attributes of different types of cactus pitaya fruits (Stenocereus griseus). Acta Hortic. 2005, 682, 645-650. [CrossRef]

19. García, L.; Valle, S.; Salinas, Y.; Joaquín, E. Physical, chemical, and antioxidant activity characterization of pitaya (Stenocereus pruinosus) fruits. Plant Foods Hum. Nutr. 2013, 68, 403-410. [CrossRef]

20. Stintzing, F.C.; Carle, R. Functional properties of anthocyanins and betalains in plants, food, and in human nutrition. Trends Food Sci. Technol. 2004, 15, 19-38. [CrossRef]

21. Herrera, M.G.; Guevara, F.; Reynoso, R.; Guzmán, S.H. Effects of maturity stage and storage on cactus berry (Myrtillocactus geometrizans) phenolics, vitamin C, betalains and their antioxidant properties. Food Chem. 2011, 129, 1744-1750. [CrossRef]

22. Guzmán, S.H.; Herrera, G.; Hernández, D.; Reynoso, R.; Guzmán, A.; Vaillant, F.; Brat, P. Physicochemical, nutritional and functional characteristics of two underutilised fruit cactus species (Myrtillocactus) produced in central Mexico. Food Chem. 2010, 121, 381-386. [CrossRef]

23. Fernández, J.A.; Almela, L.; Obón, J.M.; Castellar, R. Determination of antioxidant constituents in cactus pear fruits. Plant Foods Hum. Nutr. 2010, 65, 253-259. [CrossRef] [PubMed]

24. Castellar, M.R.; Solano, F.; Obón, J.M. Betacyanin and other antioxidants production during growth of Opuntia stricta (Haw.) fruits. Plant Foods Hum. Nutr. 2012, 67, 337-343. [CrossRef] [PubMed]

25. Georgé, S.; Brat, P.; Alter, P.; Amiot, M.J. Rapid determination of polyphenols and vitamin C in plant-derived products. J. Agric. Food Chem. 2005, 53, 1370-1373. [CrossRef]

26. Vergara, C.; Saavedra, J.; Sáenz, C.; García, P.; Robert, P. Microencapsulation of pulp and ultrafiltered cactus pear (Opuntia ficus-indica) extracts and betanin stability during storage. Food Chem. 2014, 157, $246-251$. [CrossRef]

27. Castro, R.; Orozco, C.; Yáñez, J. Analysis of clarification process of purple cactus pear (Opuntia ficus indica) juice by ultrafiltration. Int. J. Eng. Sci. Technol. 2014, 3, 1462-1466.

28. Moussa, T.E.; El-Samahy, S.K.; Rohn, S.; Kroh, L.W. Flavonols, betacyanins content and antioxidant activity of cactus Opuntia macrorhiza fruits. Food Res. Int. 2011, 44, 2169-2174. [CrossRef]

29. Pérez, M.G.; García, F.; Barragán, B.E. Comparative analysis of betalain content in Stenocereus stellatus fruits and other cactus fruits using principal component analysis. Int. J. Food Prop. 2016, 19, 326-338. [CrossRef]

30. Georgiev, V.G.; Weber, J.; Kneschke, E.M.; Denev, P.N.; Bley, T.; Pavlov, A.I. Antioxidant activity and phenolic content of betalain extracts from intact plants and hairy root cultures of the red beetroot Beta vulgaris cv. Detroit dark red. Plant Foods Hum. Nutr. 2010, 65, 105-111. [CrossRef]

31. Butera, D.; Tesoriere, L.; Di Gaudio, F.; Bongiorno, A.; Allegra, M.; Pintaudi, A.M.; Kohen, R.; Livrea, M.A. Antioxidant activities of Sicilian prickly pear (Opuntia ficus indica) fruit extracts and reducing properties of its betalains: Betanin and indicaxanthin. J. Agric. Food Chem. 2002, 50, 6895-6901. [CrossRef]

32. Zafra, Q.Y.; Cruz, N.; Ramírez, E.; Delgado, L.; Villanueva, J.; Alanís, E. Effects of ultrasound treatment in purple cactus pear (Opuntia ficus-indica) juice. Ultrason. Sonochem. 2013, 20, 1283-1288. [CrossRef] [PubMed]

33. Tenore, G.C.; Novellino, E.; Basile, A. Nutraceutical potential and antioxidant benefits of red pitaya (Hylocereus polyrhizus) extracts. J. Funct. Foods 2012, 4, 129-136. [CrossRef] 
34. Nakashima, K.K.; Bastos, E.L. Rationale on the High Radical Scavenging Capacity of Betalains. Antioxidants 2019, 8, 222. [CrossRef] [PubMed]

35. Cai, Y.; Sun, M.; Corke, H. Antioxidant activity of betalains from plants of the Amaranthaceae. J. Agric. Food Chem. 2003, 51, 2288-2294. [CrossRef] [PubMed]

36. Tenore, G.C.; Calabrese, G.; Stiuso, P.; Ritieni, A.; Giannetti, D.; Novellino, E. Effects of Annurca apple polyphenols on lipid metabolism in HepG2 cell lines: A source of nutraceuticals potentially indicated for the metabolic syndrome. Food Res. Int. 2014, 63, 252-257. [CrossRef]

37. Pap, N.; Mahosenaho, M.; Pongrácz, E.; Mikkonen, H.; Jaakkola, M.; Virtanen, V.; Myllykoski, L.; Horváth-Hovorka, Z.; Hodúr, C.; Vatai, G.; et al. Effect of ultrafiltration on anthocyanin and flavonol content of black currant juice (Ribes nigrum L.). Food Bioprocess Tech. 2012, 5, 921-928. [CrossRef]

38. Yilmaz, E.; Bagci, P.O. Pduction of phytotherapeutics from broccoli juice by integrated membrane processes. Food Chem. 2018, 242, 264-271. [CrossRef]

39. Luo, H.; Cai, Y.; Peng, Z.; Liu, T.; Yang, S. Chemical composition and in vitro evaluation of the cytotoxic and antioxidant activities of supercritical carbon dioxide extracts of pitaya (dragon fruit) peel. Chem. Cent. J. 2014, 8, 1. [CrossRef]

40. Fathordoobady, F.; Mirhosseini, H.; Selamat, J.; Manap, M.Y.A. Effect of solvent type and ratio on betacyanins and antioxidant activity of extracts from Hylocereus polyrhizus flesh and peel by supercritical fluid extraction and solvent extraction. Food Chem. 2016, 202, 70-80. [CrossRef]

41. Liang, N.; Kitts, D.D. Antioxidant property of coffee components: Assessment of methods that define mechanisms of action. Molecules 2014, 19, 19180-19208. [CrossRef]

42. Cassano, A.; Tasselli, F.; Conidi, C.; Drioli, E. Ultrafiltration of Clementine mandarin juice by hollow fibre membranes. Desalination 2009, 241, 302-308. [CrossRef]

43. Mercado, G.; Laura, A.; Alvarez, E. Effect of pectin on the interactions among phenolic compounds determined by antioxidant capacity. J. Mol. Struct. 2020, 1199, 126967. [CrossRef]

44. Yen, G.C.; Duh, P.D.; Tsai, H.L. Antioxidant and pro-oxidant properties of ascorbic acid and gallic acid. Food Chem. 2002, 79, 307-313. [CrossRef]

45. Yilmaz, Y.; Toledo, R.T. Major flavonoids in grape seeds and skins: Antioxidant capacity of catechin, epicatechin, and gallic acid. J. Agric. Food Chem. 2004, 52, 255-260. [CrossRef] [PubMed]

46. Yin, H.; Zhang, Q.; Zhou, Y.; Ma, Q.; Zhu, L.; Ai, S. Electrochemical behavior of catechol, resorcinol and hydroquinone at graphene-chitosan composite film modified glassy carbon electrode and their simultaneous determination in water samples. Electrochim. Acta 2011, 56, 2748-2753. [CrossRef]

47. Dehbi, F.; Hasib, A.; Bouaziz, M.; Ouatmane, A.; Elbatal, H.; Jaouad, A.; Sayadi, S. Effect of phenolic compounds and betalain pigments on the antioxidant capacity of Moroccan prickly pear juices. Nat. Technol. 2013, 9, 2 .

48. Abdel, E.S.S.; Nagaty, M.A.; Salman, M.S.; Bazaid, S.A. Phytochemicals, nutritionals and antioxidant properties of two prickly pear cactus cultivars (Opuntia ficus indica Mill.) growing in Taif, KSA. Food Chem. 2014, 160, 31-38. [CrossRef]

49. Miguel, M.G. Betalains in Some Species of the Amaranthaceae Family: A Review. Antioxidants 2018, 7, 53. [CrossRef]

50. Gandía, F.; Escribano, J.; García, F. The role of phenolic hydroxy groups in the free radical scavenging activity of betalains. J. Nat. Prod. 2009, 72, 1142-1146. [CrossRef]

51. AOAC. Official Methods of Analisys; Association of Official Analytical Chemists (AOAC): Washington, DC, USA, 1996.

52. Laurentin, A.; Edwards, C.A. A microtiter modification of the anthrone-sulfuric acid colorimetric assay for glucose-based carbohydrates. Anal. Biochem. 2003, 315, 143-145. [CrossRef]

53. Re, R.; Pellegrini, N.; Protoggente, A.; Pannala, A.; Yang, M.; Rice, C. Antioxidant activity applying an improved ABTS radical cation decolorization assay. Free Radic. Biol. Med. 1999, 26, 1231-1237. [CrossRef]

54. Molyneux, P. The use of the stable radical dipheylpicrylhydrazyl (DPPH) for estimating antioxidant activity. Songklanakarin J. Sci. Technol. 2004, 26, 211-219.

(C) 2020 by the authors. Licensee MDPI, Basel, Switzerland. This article is an open access article distributed under the terms and conditions of the Creative Commons Attribution (CC BY) license (http://creativecommons.org/licenses/by/4.0/). 